\title{
FLOREM - a floristic database on mountain ecosystems
}

\author{
Thomas Spiegelberger \& Claude Bernard-Brunet
}

\begin{abstract}
FlorEM (GIVD ID EU-FR-002) is a database restricted to the flora of the montane and subalpine zones of the French Alps and Pyrenees. More than 5,000 line transects and plot data with the abundance of each species have been inventoried since the 1970s, of which a part is precisely geolocalized by GPS. The metadata of each relevé includes information on abiotic (exposition, altitude, etc.), biotic (bed rocks, physical-chemical soil analyses, etc.) and agronomic variables (productivity, type of cattle, stocking rates, etc.). The majority of the relevés are located in the Northern French Alps (27\%, in particular in Vanoise, Beaufortin, Oisans and Maurienne), the Southern French Alps (50\%, Vercors, Briançonnais) and in the Pyrenees (13\%). Approximately half of the relevés are located above 2,000 m, 1/4 between 1,500 - 2,000 m, and 1/4 below 1,500 m. Two sites in the Department of Isere have been equipped with 12 paired plots, one grazed and the other not grazed for more than 20 years (Haut-Plateaux du Vercors) or 30 years (Alpe d'Huez). The vegetation has been sampled regularly through the study period. These plots constitute an asset of first importance of FlorEM allowing to follow the interactions between climate change and change of pastoral management.
\end{abstract}

Keywords: French Alps; French Pyrenees; high elevation; montane zone; subalpine zone.

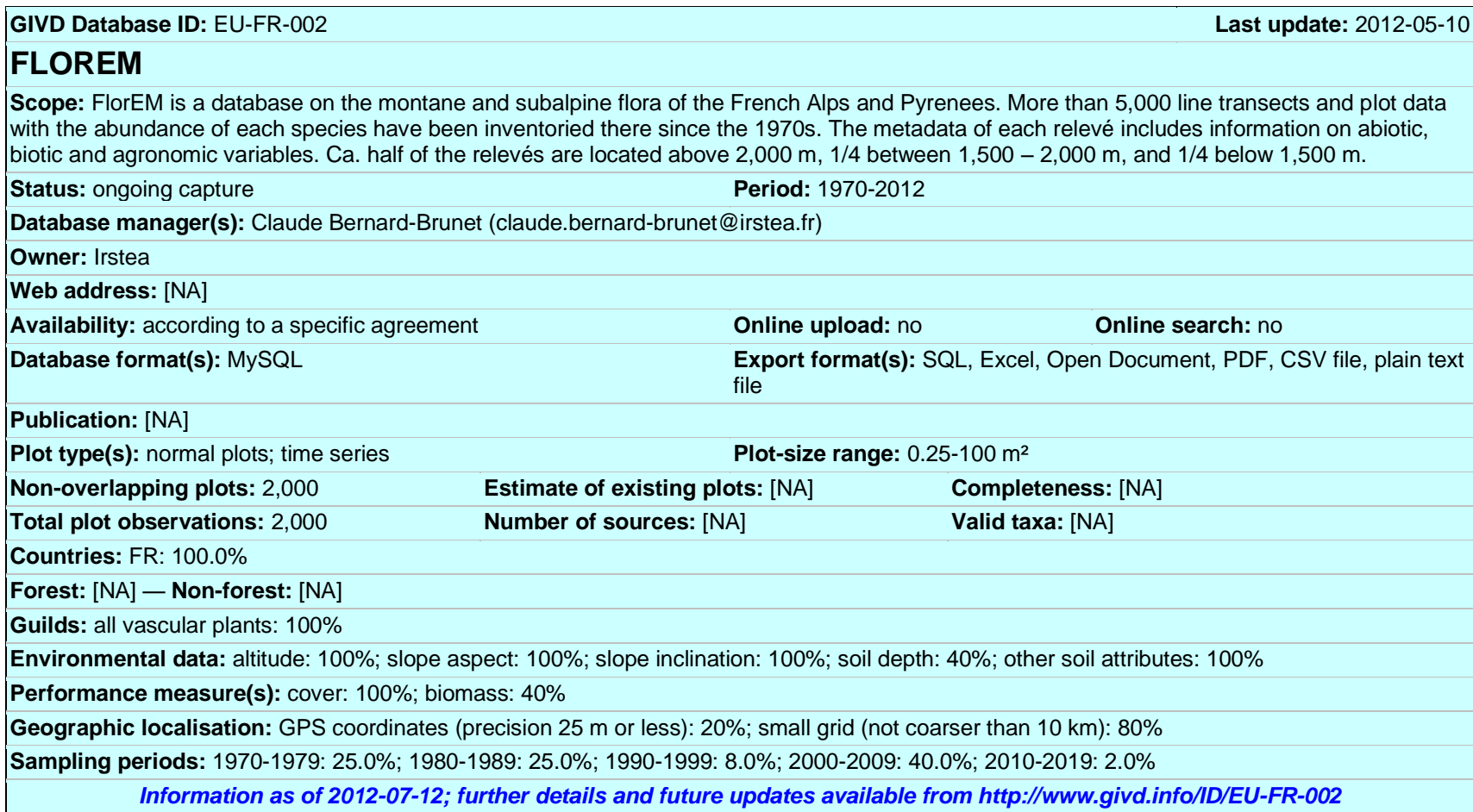

Thomas Spiegelberger* (thomas.spiegelberger@irstea.fr), Claude Bernard-Brunet (claude.bernard-brunet@irstea.fr) Research Unit EMGR, Mountain Ecosystems, Irstea, 2 Rue de la Papeterie, 38402 Grenoble, FRANCE

*Corresponding author 